Portland State University

PDXScholar

Spring 3-1-2017

\title{
Factors Influencing Recruitment of Non-Accounting Business Professionals Into Internal Auditing
}

\author{
Geoffrey D. Bartlett \\ Utah Valley University \\ Joleen Kremin \\ Portland State University, jkremin@pdx.edu \\ K. Kelli Saunders \\ University of Nebraska-Lincoln \\ David A. Wood \\ Brigham Young University
}

Follow this and additional works at: https://pdxscholar.library.pdx.edu/busadmin_fac

Part of the Accounting Commons

Let us know how access to this document benefits you.

\section{Citation Details}

Bartlett, G. D., Kremin, J., Saunders, K. K., \& Wood, D. A. (2017). Factors Influencing Recruitment of NonAccounting Business Professionals into Internal Auditing. Behavioral Research in Accounting. Spring, Vol. 29, No. 1, pp. 119-130.

This Post-Print is brought to you for free and open access. It has been accepted for inclusion in Business Faculty Publications and Presentations by an authorized administrator of PDXScholar. Please contact us if we can make this document more accessible: pdxscholar@pdx.edu. 


\title{
Factors Influencing Recruitment of Non-Accounting Business Professionals into Internal Auditing
}

\author{
Geoffrey D. Bartlett \\ Utah Valley University \\ geoffrey.bartlett@uvu.edu \\ Joleen Kremin \\ Portland State University \\ jkremin@pdx.edu \\ K. Kelli Saunders \\ University of Nebraska - Lincoln \\ kelli.saunders@unl.edu \\ David A. Wood \\ Brigham Young University \\ davidwood@byu.edu
}

October 2016

The authors appreciate the helpful comments and suggestions from the editor Rick Hatfield, an anonymous reviewer, Elizabeth Almer, Rainer Lenz, Kun Liu, Chris Nolder, Michael Robinson, Samantha Schachner, and Bryan Stewart. 


\title{
Factors Influencing Recruitment of Non-Accounting Business Professionals into Internal Auditing
}

\begin{abstract}
:
This paper examines factors affecting non-accounting business professionals' willingness to work in internal auditing. In a 2 x 6 experiment with 502 participants from across the country, we find that, in contrast to prior research examining accountants, business professionals have relatively favorable views of internal audit. Although they hold favorable views, participants were still less likely to apply for a position labeled as internal audit than an identical position with an alternate label. Varying the structure of internal audit, including job responsibilities, career path, and sourcing arrangement, did not affect participants' willingness to apply for an internal audit position. We also find that high academically performing participants are less likely to apply to work in internal audit. Finally, based on an additional survey of 46 business students, we find that lower academically performing students would be more interested in internal audit if it paid more, but higher academically performing students would be more interested if internal audit performed more interesting work, was in a preferred company/field, or if they had more understanding of the profession.
\end{abstract}

Key Words: Internal Audit, Hiring Decisions, Business Professionals, Outsourcing, Management Training Ground

Data Availability: Contact the authors. 


\section{INTRODUCTION}

This paper complements two recent papers that examine how accounting students (Burton, Starliper, Summers, and Wood 2015) and external auditors (Bartlett, Kremin, Saunders, and Wood 2016) perceive internal auditors and their willingness to work in internal auditing versus another career. We extend these prior studies by examining how non-accounting business professionals perceive internal audit and their interest in working in internal auditing. Thus, the three studies work together to provide a relatively complete view of how the business world perceives internal auditing.

Studying perceptions of internal auditing is important given that a synthesis of extant literature indicates that relevant stakeholders (e.g., audit committees, management, etc.) are generally dissatisfied with internal audit functions (IAFs) and that IAFs may risk becoming marginalized within organizations (Lenz and Hahn 2015) and governments (Lenz and Sarens 2012). In addition, internal auditing faces critical challenges in recruiting talent (GrantThornton 2014; Iyer 2014; Selim, Allegrini, D'Onza, Koutoupis, and Melville 2014; IIA 2015). Because prior research shows that internal audit is valuable to organizations and is facing recruiting difficulties, it is important to understand perceptions of the profession in order to discover ways to attract more talent to the profession. Given that effective IAFs demand an increasingly broad skill set, it is important to understand how business professionals perceive internal auditing as they are being actively recruited into the profession (IIA 2015). ${ }^{1}$

Based on results from a $2 \times 6$ between-subjects experiment using 502 business students from four universities we find several key results including:

\footnotetext{
${ }^{1}$ The internal audit profession actively recruits professionals from a variety of backgrounds outside of accounting including marketing, finance, IT, and engineering (IIA 2011; Murphy 2013). Indeed, a recent report by the IIA indicates a pressing need to recruit professionals with appropriate skill sets to address critical risk areas, including cybersecurity, IT, and the increasingly complex regulatory environment (IIA 2015).
} 
- Business professionals, unlike accountants, have largely positive perceptions of internal auditing (e.g., internal auditors are respected, enjoy excellent compensation and benefits, perform meaningful work, and have excellent promotion and career opportunities).

- Business professionals, consistent with accountants, believe other business professionals hold negative stereotypes of internal auditing.

- Business professionals are less willing to apply for positions in internal auditing than similar positions outside the IAF.

- Business professionals are not more inclined to work in internal audit by varying the structure of the IAF, including expanding IAF duties to include consulting, using the IAF as a management training ground (MTG), and outsourcing the IAF to an external service provider.

In directly analyzing what factors influence interest in working in internal auditing, we find that participants with more favorable impressions of internal auditing were more likely to apply to work in internal audit. Conversely, participants who self-identify as top performers in their class were less interested in internal auditing positions.

In order to provide direction on how companies and the profession can better attract business professionals into internal auditing, we conducted an additional survey of 46 nonaccounting business school students from across the country. We find that lower academically performing students would be more interested in internal auditing if they were paid more. In contrast, higher academically performing students would be more interested in internal auditing if they performed less boring/tedious work, worked in a preferred company/field, and if they had more understanding of the profession.

This study replicates and extends the findings of Burton et al. (2015) and Bartlett et al. (2016) to provide a more complete picture of the current interest in and perceptions of internal auditing. Combined, the results of these three studies show that the internal auditing profession has room to improve in attracting high numbers of business professionals, accounting students, 
and external auditors to work in internal auditing. Internal auditing plays an integral role in governance and these results suggest the need to improve both the quantity and quality of individuals interested in working in internal auditing, and the results of this study should be helpful in identifying areas where internal audit advocacy groups, such as the Institute of Internal Auditors (IIA), can focus outreach and recruiting efforts.

We proceed with the rest of the paper as follows: in the next section, we develop our hypotheses and research question. We then describe the methodology used to investigate our predictions, after which we report our results and then conclude the paper.

\section{THEORY DEVELOPMENT, HYPOTHESES, AND RESEARCH QUESTION}

Prior research provides evidence that high-quality IAFs have the ability to significantly impact organizations. ${ }^{2}$ A critical component of having a high quality IAF is attracting talented individuals into available positions. Without the "raw materials" of talented individuals, internal audit will struggle to achieve its mission.

Prior practice literature and academic literature suggests IAFs struggle to attract a large number of high quality individuals to apply for positions. From the practice literature, Murphy (2013) predicts that "by 2018, large companies could have a[n internal audit] talent shortfall of up to $30 \%$. ." In addition, The IIA indicates that attracting and retaining talent is a critical priority for many in the profession (IIA 2015). Recent academic studies raise similar concerns showing

\footnotetext{
${ }^{2}$ For example, high-quality IAFs are associated with high quality corporate governance and risk management (Gramling, Maletta, Schneider, and Church 2004; Julien and Reiger 2011; Trotman 2013; Deloitte 2014; Lenz and Hahn 2015), as well as financial reporting and fraud prevention and detection (ACFE 2012). Additionally, prior work shows that internal audit has significant influence on risk assessment (Sarens and De Beelde 2006; Asare, Davidson, and Gramling 2008), financial performance (Jiang, Messier, and Wood 2016), operational and compliance risk (Carcello, Eulerich, Masli, and Wood 2015), safeguarding of assets (Beasley, Carcello, Hermanson, and Lapides 2000; Coram, Ferguson, and Moroney 2008), financial statement quality (Prawitt, Smith, and Wood 2009; Prawitt, Sharp, and Wood 2012; Ege 2015; Abbott, Daugherty, Parker, and Peters 2016), external audit fees (Felix Jr, Gramling, and Maletta 2001; Messier, Reynolds, Simon, and Wood 2011; Prawitt, Sharp, and Wood 2011; Abbott, Parker, and Peters 2012) and internal control strength (Lin, Pizzini, Vargus, and Bardhan 2011; Abbott et al. 2012; Abbott et al. 2016).
} 
that accounting students and external auditors have negative perceptions of internal auditing and are less willing to apply for "internal audit" positions relative to identical positions with an alternate label (Burton et al. 2015; Bartlett et al. 2016).

One area not addressed in prior studies that may ameliorate these problems is the potential to recruit non-accounting business professionals into IAFs. Business professionals are particularly attractive to hire for internal auditing because of the need for IAFs to possess a diverse skill set in order to address critical risks faced by companies for which accounting skills alone may not be adequate (PwC 2015). Indeed, internal audit thought leaders note that internal audit needs a diverse group of business professionals in order to achieve its objectives (e.g., IIA 2011; Chambers 2012a, 2012b, 2012c).

In trying to attract business professionals to work in internal auditing, the profession may face an uphill battle. Richard Chambers, the Global CEO of the IIA, acknowledged that the perception of internal auditors by business professionals may not be positive, admitting that there is a "grain of truth" to the portrayal of internal auditors' reputation as "tedious, intimidating or even boring" (2014). Similarly, a representative of one public accounting firm noted "certain companies do not necessarily hold internal audit in high esteem," and a report by Grant Thornton indicates that 40 percent of Chief Audit Executives (CAEs) identify “perception of internal audit within the organization" as a barrier to delivering the greatest value (Hoffelder 2012; GrantThornton 2015).

Business professionals' perception of internal auditing may be influenced by several different sources. As business professionals interact with accountants that hold a negative perception of internal auditing, that perception can spread. Business professionals may also have similar negative impressions based on their own experiences with internal audit (Chambers 
$2012 \mathrm{~b}, 2014)$. Because perceptions and stereotypes are powerful predictors of behavior, negative perceptions are likely to lead to a decreased willingness to join the profession (Burton et al. 2015; Bartlett et al. 2016). Accordingly, we predict:

H1: Business professionals have negative perceptions of internal audit as a profession. H2: Business professionals will be less likely to apply for a position when labeled "internal audit" as compared to the same position labeled as a general employee position.

The structure of the IAF can vary widely (IIA 2015). Three key areas in which the structure of internal audit varies between organizations are: primary job responsibilities (assurance vs. consulting work), career path (structuring internal audit as a MTG vs. traditional in-house IAF career path), and sourcing arrangement (in-house IAF vs. outsourced IAF). There are reasons to believe the structural differences of IAFs may influence stereotypes about the IAF and consequently willingness to work in an IAF.

First, with regard to primary job responsibilities, assurance work, which is similar to external auditing work, is often not viewed positively within the internal auditing profession and often not perceived to contribute significant value to the organization (Gramling, Nuhoglu, and Wood 2013). Consulting tasks, on the other hand, can differ significantly from audit or other typical accounting tasks, and Burton et al. (2015) found that students with work experience were more interested in working in internal audit if the IAF performed primarily consulting work and was used as a MTG. Further, if the IAF is used as a MTG, it is less likely that job applicants will view the position as a commitment to a career entirely in internal audit, but rather as a steppingstone to other management positions within the organization. Finally, with regard to the sourcing arrangement of the IAF, prior research has identified several benefits associated with outsourcing the IAF. These benefits include increased perceptions of objectivity, lower risk of misstated financial statements, and increased reliance on the IAF by managers and external auditors (e.g., 
Ahlawat and Lowe 2004; Glover, Prawitt, and Wood 2008; Brandon 2010; Desai, Gerard, and

Tripathy 2011; Burton, Emett, Simon, and Wood 2012; Prawitt et al. 2012). Accordingly, we

expect that the structure of the IAF will impact preferences toward working in internal audit; specifically:

H3a: Business professionals will be less likely to apply for a position when the IAF performs more assurance work than consulting work.

H3b: Business professionals will be less likely to apply for a position when the IAF is not used as a MTG than when it is used as a MTG.

H3c: Business professionals will be less likely to apply for a position when the IAF is performed in-house rather than outsourced to a third party.

\section{METHODOLOGY}

\section{Participants}

We administered an experiment to undergraduate and graduate non-accounting business students from four different universities. ${ }^{3}$ The universities included both public and private institutions that are diverse in terms of size and location helping to ensure that the results are less likely to be influenced by a single source (e.g., one university that emphasizes careers in IA more than another or one university where the IAF is generally cast in a favorable or unfavorable light). ${ }^{4}$ Professors emailed students requesting their participation and students completed the online case at their own discretion.

A total of 634 students completed the online case. Of these, 132 (21 percent) failed manipulation check questions, resulting in a final sample size of 502 participants. ${ }^{5}$ Table 1

\footnotetext{
${ }^{3}$ Clune and Gramling (2012) report that recent university graduates make up a large portion of the IAF hiring pool (58 percent). Moreover, IAFs are increasingly recruiting talent from a broad array of backgrounds other than accounting, and have begun placing greater emphasis on graduate-level education (TapestryNetworks 2011). In unreported results, we test whether work experience affects our results and find that it does not, suggesting our results are likely to apply to non-students as well.

${ }^{4}$ Control variables that were included to test for institutional influences revealed no differences between institutions.

${ }^{5}$ All participants were asked whether the position was described as an internal audit or generic employee position.

Further manipulation check questions were specific to the condition to which the participant was assigned
} 
provides specific demographic information for the participants. Randomization of participants to conditions appears to have been successful in that there were no significant differences between conditions in terms of age, internships performed, job offer acceptance, experience, or gender and our reported results are inferentially similar to those reported if we included these variables as covariates.

\section{(Insert Table 1 about Here)}

\section{Experimental Case Study and Independent Variables}

The experimental case study was patterned after Burton et al. (2015) and Bartlett et al. (2016) and used a $2 \times 6$ between-subjects design. The participants read a brief description for a job position. In the first paragraph of the manipulation, we varied whether the position was labeled specifically as an internal audit position or a more general "employee" position. ${ }^{6} \mathrm{We}$ chose the general "employee" label for the non-internal audit description since this could refer to a variety of job positions within an organization, and would therefore be likely to attract interest from candidates from a variety of different backgrounds (e.g., it was not specific to marketing finance, operations, etc.). Everything else was held constant in the first paragraph of the job description other than the labels (except in the outsourced condition, as described below).

Participants in conditions other than the baseline (i.e., general employee) or outsourcing conditions read a subsequent paragraph where we manipulated the position description in more detail. Specifically, we manipulated the description of the position with regards to job

(outsourced vs. in-house, management training ground vs. no management training ground, or assurance vs. consulting). These manipulations were relatively subtle (i.e., only a few words were varied). Moreover, students often perform these types of studies quickly. Therefore, though unfortunate, the relatively high manipulation check failure rate is not surprising. We note that there were no differences in demographic variables (e.g., age, GPA, job offer acceptance, months of business experience, etc.) between those that passed manipulation checks and those that did not except that those who had performed an internship were more likely to miss the manipulation check question (p-value $<0.10)$.

${ }^{6}$ For comparability purposes across papers, we used the same opening paragraph for our job description as Burton et al. (2015) used for their job description in experiment 1 . The only change we made was using the general "employee" label as opposed to labeling the position as "accounting." 
responsibilities (primarily consulting or primarily assurance) and career path (MTG or promotion within the department [i.e., non-MTG]). ${ }^{7}$ We also included a condition where we manipulated the sourcing arrangement of the IAF by describing the company hiring the internal auditors as either a "large company" or a "large company that provides outsourced services to other companies."

\section{Dependent Variable}

We test H1 by measuring participants' perceptions of the internal audit profession as a whole. Specifically, we ask participants their agreement with statements about: 1) negative stereotypes of internal auditors, 2) respect for internal auditors, 3) compensation and benefits of internal auditors, 4) meaningfulness and satisfaction of work performed by internal auditors, 5) promotion and career opportunities in internal auditing, and 6) the work-life balance of internal auditors (see Table 2, Panel A for exact question wording). All questions were measured on a seven-point scale with negative three labeled "Strongly Disagree," zero labeled "Neither Agree nor Disagree," and three labeled "Strongly Agree."

$\mathrm{H} 2$ through $\mathrm{H} 3 \mathrm{c}$ involve the participants' interest in applying for the job position. After viewing the job description information, we asked participants "Would you apply for this position for full time employment?" with participants answering yes or no. ${ }^{8}$ We also asked the following question to those in the internal audit (general employee) condition: "You find out there is an identical job

posting for a similar company with one difference. The new job would hire you to work in a department other than the internal audit function of the company (in the internal audit function of

\footnotetext{
${ }^{7}$ For the assurance and consulting conditions, we again used the same descriptions as those used in Burton et al. (2015) for comparison purposes. As Burton et al. $(2015,20)$ point out, the descriptions were "patterned after the IIA definitions of assurance and consulting services."

${ }^{8}$ We also measured our participants' interest in the job with the question: "How interested are you in the job?" This question was measured with a seven-point likert scale, with greater values indicating greater interest in the position. The results from this measure are qualitatively similar to those for the "apply" measure.
} 
the company). Which job would you be more interested in pursuing?" Answers were measured on a seven-point scaled anchored at " 1 - Strongly prefer the job in the internal audit function of the company," "4 - Prefer each position equally," and "7 - Strongly prefer the job in a department other than the internal audit function of the company." This alternative measure allows for a strong, within-subjects test of whether they are more interested in internal auditing vs. a different position. RESULTS

Panel A of Table 2 presents the results testing H1. Contrary to H1, our results suggest that participants believe internal auditors are highly respected by other business professionals, perform meaningful and satisfying work, and have excellent promotion and career opportunities (all t-tests measured against the midpoint of 0 are significant at $p$-value $<0.01$ ). Interestingly, these views align with those of accounting students (Burton et al. 2015), but not external auditors (Bartlett et al. 2016). Our results also indicate that participants believe that internal auditors have excellent promotion and career opportunities $(\mathrm{p}<0.01)$, which is consistent with the views of both accounting students and external auditors documented in previous studies (Burton et al. 2015; Bartlett et al. 2016). However, while our participants largely exhibit positive perceptions of IA, they significantly agree that other business professionals have negative stereotypes of internal auditing ( $\mathrm{p}$-value $<0.01$ ), which is with both accounting students and external auditors (Burton et al. 2015; Bartlett et al. 2016). Our participants neither agreed nor disagreed that internal auditors have excellent work-life balance ( $\mathrm{p}$-value $>0.10$ ). Overall, these results do not support H1. Specifically, our participants largely held favorable perceptions of internal auditing, even though they believed other business professionals have negative stereotypes of internal auditing. ${ }^{9}$

\footnotetext{
${ }^{9} \mathrm{We}$ also asked participants two questions regarding the frequency in which internal auditing is discussed as a career for students and the tone of discussions about internal auditing at their universities (see Table 2, Panel B).
} 


\section{(Insert Table 2 about Here)}

To test H2, we conducted a chi-squared test for the "apply" variable across all conditions individually and in the aggregate (see Panel A of Table 3). We also conducted an ANOVA for all conditions (see Panel C of Table 3). Across all conditions, participants were 12.7 percent less likely to apply for the position labeled as internal audit than the position labeled as general employee, which was statistically significant in both the univariate analysis (see Panel A, p-value $<0.01$ ) and multivariate analysis (see Panel C, p-value $<0.01$ ). These results support H2.

As previously described, we also asked participants whether they would be more interested in an internal audit (non-internal audit) position, given their experimental condition. Panel $\mathrm{F}$ of Table 3 shows that participants had significantly more interest in pursuing a position not specifically labeled as internal audit ( $\mathrm{p}$-value $<0.01)$. This result provides complementary evidence, using a strong within-subject design, supporting H2.

\section{(Insert Table 3 about Here)}

We next turn to a discussion of our results testing $\mathrm{H} 3 \mathrm{a}, \mathrm{H} 3 \mathrm{~b}$, and $\mathrm{H} 3 \mathrm{c}$. Our overall ANOVA results (Panel C of Table 3) show a statistically significant main effect for our Condition variable, which captured whether participants were assigned to the baseline, assurance, consulting, management training ground, non-management training ground, or outsourced condition ( $\mathrm{p}$-value $<0.01$ ). However, there was not a significant interaction with the internal audit variable, which measured whether participants were assigned to the internal audit condition or the general employee condition (p-value $>0.10$ ). The descriptive statistics presented in Panel A of Table 3 and the graph of those statistics in Panel B of Table 3 reveal an interesting pattern. The pattern shows that it did not matter how the internal audit position was described, career for students" ( $\mathrm{p}$-value $<0.01$ ). However, participants significantly agreed with the statement: "At my university, discussion about internal auditing is positive" ( $\mathrm{p}$-value $<0.01$ ). 
there was no significant difference in how participants viewed the position. That is, when we compare responses for condition for only participants in the internal audit position (see Panel D of Table 3), there is no statistically significant difference between any of the conditions (p-value $>0.10)$. Combined, these results provide no support for $\mathrm{H} 3 \mathrm{a}, \mathrm{H} 3 \mathrm{~b}$, and $\mathrm{H} 3 \mathrm{c}$. That is, for those participants in the internal audit conditions, job responsibilities, career path, and sourcing arrangement had no effect on willingness to apply to work in internal auditing.

In contrast, there are significant differences in participants' willingness to apply for positions in the non-internal audit conditions (see Panel E, p-value $<0.01$ ). Participants in the general employee condition had the strongest preference to apply for the position when it was described as a non-management training ground (75.8\% chose to apply), followed in descending order by: management training ground $(68.6 \%)$, consulting $(60.0 \%)$, outsourced $(45.7 \%)$, assurance (42.5\%), and the baseline condition (42.4\%) (see Table 3, Panel A).

\section{ADDITIONAL TESTING}

To further examine factors that influence preferences toward working in internal audit, we use logistic regression to investigate how the factors listed in Table 2 impact the choice to apply for a position in internal auditing. We average the perception questions in Panel A of Table 2 into a single measure capturing their opinion of internal auditing. We combine how participants' universities discuss internal auditing by averaging the two variables reported in Panel B of Table 2. We also include participants score on 14 multiple choice questions that were taken from a practice CIA exam to measure internal audit ability, and then we ask participants to self-assess whether they are a top performer in their class as a measure of their general ability. We include the following control variables in the regression: gender, whether participants had completed an internship, and how many months of business experience participants had. 
We present regression results in Table 4. The results show that participants are more willing to apply to work in internal audit if they have more favorable views of internal audit characteristics ( $p$-value $<0.001)$. The more positive the discussion of internal auditing at a university is almost statistically significant at conventional levels ( $p$-value $=0.133$ ). Participants internal audit knowledge did not impact the willingness to apply for an internal audit position (pvalue $>0.10$ ), but self-assessed high performers are less likely to want to work in internal auditing ( $\mathrm{p}$-value $<0.05$ ). The control variables are not significant at conventional levels ( $\mathrm{p}$ values $>0.10)$.

\section{(Insert Table 4 about Here)}

In an effort to provide additional insight into how internal auditing can attract more employees, we report survey results of 46 students from across the country asking them what would make internal auditing more attractive to them as a career. ${ }^{10}$ We had a research assistant create categories and group the responses into categories for analysis. Respondents could provide multiple suggestions, so each suggestion provided is considered as an independent unit of analysis. We split the results based on whether participants were above or below the median GPA of 3.6 to see if high performing and low performing students differ in their perception of what would make internal auditing more interesting to them.

We present the results in Table 5. The results show that high and low performing participants differ in what would attract them to internal audit. ${ }^{11}$ Whereas lower performing students would be more interested if offered greater compensation (43.3 percent compared to

\footnotetext{
${ }^{10}$ We used Amazon's Mechanical Turk to solicit participation. We required that participants be located in the United States and then, based on their self-responses, that participants be currently enrolled in a U.S. university business school and majoring in something other than accounting. We paid participants $\$ 1$ for participating in the short survey. Participants came from 43 different universities, 10 different majors, and all class standing (freshman to MBA). We solicited participation from 50 MTurk workers (and only collected one sample) - four were dropped because they did not provide compete responses (GPA) for inclusion in the study.

${ }^{11} \mathrm{~A}$ chi-square test shows that the distribution of answers is significantly different for high/low performing students (p-value $<0.01$ ).
} 
15.6 percent of high performing students), high performing students deemed other factors important. Specifically, high (low) performing students reported that the following factors would make internal audit more appealing: 21.9 percent (13.3 percent) reported a desire to perform more interesting work; 12.5 percent ( 3.3 percent) stated interest in working with a preferred company/field; and 12.5 percent ( 0 percent $)$ would like more understanding of the profession. Finally, 21.9 percent of high performers indicated that nothing would make internal audit more appealing, compared to only 10 percent of low performers. This later finding supports the regression results suggesting that high performers are less interested in working in internal audit than low performers.

These findings suggest several avenues the internal auditing profession can pursue to increase interest in the profession. Especially interesting is that high performers and low performers would be attracted based on different factors. Though a minority of high-performing participants specifically indicated a limited understanding of the profession, a review of responses of high-performing participants revealed several misconceptions of what internal audit entails. For example, participants believe that work performed by the IAF is heavily dependent on math/numbers, is entirely accounting related, does not utilize technology, and is not interactive/does not deal with people. Overall, these results suggest that participants lack awareness of career opportunities in internal audit for professionals with non-accounting backgrounds. Understanding the factors that would increase interest in the profession as well as misconceptions of work performed by internal auditors should help companies and the IIA better tailor their outreach and recruitment efforts to high-quality non-accounting business professionals.

(Insert Table 5 about Here) 


\section{CONCLUSION}

This paper examines various factors that affect business professionals' willingness to work in IAFs. We find that although our participants believe that other business professionals hold negative stereotypes of internal audit, our participants themselves held generally favorable views of internal audit. Specifically, our participants view internal auditors as being highly respected by other business professionals, having excellent compensation and benefits, performing meaningful and satisfying work, and having excellent promotion and career opportunities. We also find that business professionals are significantly less likely to apply for a position labeled specifically as internal audit compared to an equally worded position labeled as a general employee. ${ }^{12} \mathrm{~A}$ more detailed examination reveals that participants are more interested in working in internal audit if they have more favorable views of internal audit characteristics. However, participants are less willing to work in internal audit if they are higher academic performers. Finally, we find that the primary job responsibilities, potential career paths, and sourcing arrangement of the IAF did not effect participants' willingness to apply for a position specifically labeled as internal audit.

In an effort to provide guidance to the profession and businesses on what they might do to better attract non-accounting business students, we survey students on what would make internal audit more appealing. We find that high and low performers responded differently. High performers would have more interest in internal audit if the work was less boring/tedious, they

\footnotetext{
${ }^{12}$ Though it may seem counterintuitive that participants believed that other business professionals held negative stereotypes of internal auditors, yet also that internal auditors are highly respected by other business professionals, we believe that the two are not mutually exclusive, and may be similar to how accountants are generally viewed in society. For example, Dimnik and Felton (2006) find that cinematic stereotypes of accountants include both positive and negative characteristics, and although accounting jobs are often depicted in an unflattering light, accountants themselves generally fare well on screen. Hence, it does not seem unreasonable to believe that others hold negative stereotypes of internal auditors, but also respect them (e.g., a person can be considered both boring and respectable).
} 
could work in a preferred company/field, and if they had more understanding of the career. In contrast, low performers are primarily interested in better pay.

This study is not without limitations, some of which offer opportunities for future research. This study, along with Burton et al. (2015) and Bartlett et al. (2016) do not examine perceptions of individuals actually working in internal audit. We encourage future research to examine internal auditors' perceptions of their own career. We would benefit by having a greater understanding of how perceptions of internal auditing affects individuals' willingness to continue working in internal audit and other internal auditing outcomes. Finally, we encourage future research that addresses specific ways to reduce negative perceptions of internal audit, particularly negative perceptions gained by working in the professional business world. 


\section{REFERENCES}

Abbott, L. J., B. Daugherty, S. Parker, and G. F. Peters. 2016. Internal audit quality and financial reporting quality: The joint importance of independence and competence. Journal of Accounting Research 54 (1): 3-40.

Abbott, L. J., S. Parker, and G. F. Peters. 2012. Internal audit assistance and external audit timeliness. Auditing: A Journal of Practice \& Theory 31 (4): 3-20.

ACFE (Association of Certified Fraud Examiners). 2012. Report to the Nations on Occupational Fraud and Abuse.

Ahlawat, S. S., and D. J. Lowe. 2004. An examination of internal auditor objectivity: In-house versus outsourcing. Auditing: A Journal of Practice \& Theory 23 (2): 149-160.

Asare, S. K., R. A. Davidson, and A. A. Gramling. 2008. Internal auditors' evaluation of fraud factors in planning an audit: The importance of audit committee quality and management incentives. International Journal of Auditing 12 (3): 181-203.

Bartlett, G. D., J. Kremin, K. K. Saunders, and D. A. Wood. 2016. Attracting applicants for inhouse and outsourced internal audit positions: Views from external auditors. Accounting Horizons 30 (1): 143-156.

Beasley, M. S., J. V. Carcello, D. R. Hermanson, and P. D. Lapides. 2000. Fraudulent financial reporting: Consideration of industry traits and corporate governance mechanisms. Accounting Horizons 14 (4): 441-454.

Brandon, D. M. 2010. External auditor evaluations of outsourced internal auditors. Auditing: A Journal of Practice \& Theory 29 (2): 159-173.

Burton, G. F., S. A. Emett, C. A. Simon, and D. A. Wood. 2012. Corporate managers' reliance on internal auditor recommendations. Auditing: A Journal of Practice \& Theory 31 (2): 151166.

Burton, G. F., M. W. Starliper, S. L. Summers, and D. A. Wood. 2015. The effects of using the internal audit function as a management training ground or as a consulting services provider in enhancing the recruitment of internal auditors. Accounting Horizons 29 (1): $115-140$.

Carcello, J. V., M. Eulerich, A. Masli, and D. A. Wood. 2015. Working paper. The value to management of using the internal audit function as a management training ground. University of Tennessee, University of Druisburg-Essen, University of Kansas and Brigham Young University. 
Chambers, R. 2012a. A dead end job? I hardly think so! Internal Auditor, Available at: http://www.theiia.org/blogs/chambers/index.cfm/post/A\%20Dead\%20End\%20Job?\%20I \%20Hardly\%20Think\%20.

Chambers, R. 2012b. Five classic myths about internal auditing. Internal Auditing, Available at: http://www.theiia.org/blogs/chambers/index.cfm?postid=188.

Chambers, R. 2012c. What's in your toolbox? Audit \& Risk (5), Available at: http://media.caspianmedia.com/document/183601fb151b9f5741a7fe66505ccc3d.pdf.

Chambers, R. 2014. Managing perceptions: What should internal auditors say on the elevator? Internal Auditing, Available at: http://www.theiia.org/blogs/chambers/index.cfm?postid=260.

Clune, R., and A. A. Gramling. 2012. Hiring recent university graduates into internal audit postitions: Insights from practicing internal auditors. Current Issues in Auditing 6 (2): A1-A14.

Coram, P., C. Ferguson, and R. Moroney. 2008. Internal audit, alternative internal audit structures and the level of misappropriation of assets fraud. Accounting \& Finance 48 (4): 543-559.

Deloitte (Deloitte Touche Tohmatsu Limited). 2014. CFO Insights: Can internal audit be a command center for risk?

Desai, N. K., G. J. Gerard, and A. Tripathy. 2011. Internal audit sourcing arrangements and reliance by external auditors. Auditing: A Journal of Practice \& Theory 30 (1): 149-171.

Dimnik, T., and S. Felton. 2006. Accountant stereotypes in movies distributed in North America in the twentieth century. Accounting, Organizations and Society 31 (2): 129-155.

Ege, M. S. 2015. Does internal audit function quality deter management misconduct? The Accounting Review 90 pp. 495-527.

Felix Jr, W. L., A. A. Gramling, and M. J. Maletta. 2001. The contribution of internal audit as a determinant of external audit fees and factors influencing this contribution. Journal of Accounting Research 39 (3): 513-534.

Glover, S. M., D. F. Prawitt, and D. A. Wood. 2008. Internal audit sourcing arrangement and the external auditor's reliance decision. Contemporary Accounting Research 25 (1): 193-213.

Gramling, A. A., M. J. Maletta, A. Schneider, and B. K. Church. 2004. The role of the internal audit function in corporate governance: A synthesis of the extant internal auditing 
literature and directions for future research. Journal of Accounting Literature 23: 194244.

Gramling, A. A., I. Nuhoglu, and D. A. Wood. 2013. A descriptive study of factors associated with the internal audit function having an impact: Comparisons between organizations in a developed and an emerging economy. Turkish Studies 14 (3): 581-606.

GrantThornton (Grant Thornton LLP). 2014. Adding internal audit value: Strategically leveraging complaince activities. Chicago, IL:

GrantThornton (Grant Thornton LLP). 2015. Competing priorities: Are CAE and audit committee priorities in sync? Chicago, IL: GrantThornton.

Hoffelder, K. 2012. Internal audit: A dead-end job? CFO.com.

IIA (The Institute of Internal Auditors). 2010. Comprehensive Body of Knowledge.

IIA (The Institute of Internal Auditors). 2011. Recruitment strategies for tomorrow's internal audit function.

IIA (The Institute of Internal Auditors). 2015. Pulse of Internal Audit.

Iyer, V. M. (IIA). 2014. Job satisfaction for internal auditors: How to retain top talent. The Institute of Internal Auditors Research Foundation.

Jiang, L., W. F. Messier, D. A. Wood. 2016. The effects of internal audit consulting services on firm performance. Working Paper, The Univeristy of Melbourne, Univeristy of Nevada, Las Vegas, and Brigham Young Univeristy.

Julien, R., and L. Reiger (Crowe Horwath LLC). 2011. Strengthening corporate governance with internal audit.

Lenz, R. 2015. Internal auditors as change agents: What a difference a year makes! The Open Auditor 3.

Lenz, R., and U. Hahn. 2015. A synthesis of emperical internal audit effectiveness literature pointing to new research opportunities. Managerial Auditing Journal 30 (1): 5-33.

Lenz, R., and G. Sarens. 2012. Reflections on the internal auditing profession: What might have gone wrong? Managerial Auditing Journal 27 (6): 532-549. 
Lin, S., M. Pizzini, M. Vargus, and I. R. Bardhan. 2011. The role of the internal audit function in the disclosure of material weaknesses. The Accounting Review 86 (1): 287-323.

Messier, Jr W. F., J. K. Reynolds, C. A. Simon, and D. A. Wood. 2011. The effect of using the internal audit function as a management training ground on the external auditor's reliance decision. The Accounting Review 86 (6): 2131-2154.

Murphy, M. 2013. Internal audit staffs need to foresee talent shortages: CEB. CFO Journal WSJ.com.

Prawitt, D. F., N. Y. Sharp, and D. A. Wood. 2011. Reconciling archival and experimental research: Does internal audit contribution effect the external audit fee? Behavioral Research in Accounting 23 (2): 187-206.

Prawitt, D. F., N. Y. Sharp, and D. A. Wood. 2012. Internal audit outsourcing and the risk of misleading or fraudulent financial reporting: Did Sarbanes-Oxley get it wrong? Contemporary Accounting Research 29 (4): 1109-1136.

Prawitt, D. F., J. L. Smith, and D. A. Wood. 2009. Internal audit quality and earnings management. The Accounting Review 84 (4): 1255-1280.

PwC (PriceWaterhouse Coopers). 2015. 2015 State of the Internal Audit Profession Study: Finding True North in a period of rapid transformation.

Sarens, G., and I. De Beelde. 2006. Internal auditors' perception about their role in risk management: A comparison between US and Belgian companies. Managerial Auditing Journal 21 (1): 63-80.

Selim, G. M., M. Allegrini, G. D'Onza, A. G. Koutoupis, and R. Melville (The Institute of Internal Auditors Research Foundation). 2014. Internal audit around the world. Altamonte Springs, FL:

TapestryNetworks (Ernst \& Young). 2011. Internal audit's evolving role: A proactive catalyst of business improvement.

Trotman, A. J. 2013. Working paper. Internal audit quality: A multi-stakeholder analysis. Bond University. 
TABLE 1

Description of Participants

\begin{tabular}{lcc}
\hline Variable & Mean & StD \\
\hline \% Male & $52.6 \%$ & $50.0 \%$ \\
Age & 23.7 & 4.4 \\
GPA & 3.51 & 0.35 \\
Number of Internships (from 1-4) & 0.99 & 1.17 \\
Accepted a Job Offer & $20.3 \%$ & $40.3 \%$ \\
Months of Business Experience & 23.2 & 33.8 \\
Credit Hours in: & & \\
$\quad$ Accounting & 5.1 & 4.3 \\
$\quad$ Finance & 4.4 & 6.0 \\
$\quad$ Information Systems & 3.3 & 3.8 \\
$\quad$ Marketing & 5.7 & 6.7 \\
$\quad$ Organizational Behavior / Strategy & 3.7 & 4.7 \\
$\quad$ Other Business Disciplines & 10.3 & 15.5 \\
\hline
\end{tabular}

Total participants, 502, who successfully passed the manipulation checks are listed. Demographic statistics are presented for responding participants as not all participants responded to every demographic question. 
TABLE 2

Tests of H1: Business Professionals Perceptions of Internal Auditing

Panel A: Perceptions of the Internal Audit Profession

\begin{tabular}{|l|l|c|c|}
\hline \multicolumn{2}{|l|}{ Attribute } & Mean (StD) & T-test: Mean = 0 \\
\hline 1. & $\begin{array}{l}\text { Other business professionals have negative } \\
\text { stereotypes about internal auditing. (stereotypes) }\end{array}$ & $0.98(1.28)$ & $\mathrm{t}=15.96^{* * *}$ \\
\hline 2. & $\begin{array}{l}\text { Professionals in internal auditing are highly } \\
\text { respected by other business professionals. } \\
\text { (respected) }\end{array}$ & $0.23(1.41)$ & $\mathrm{t}=3.43^{* * *}$ \\
\hline 3. & $\begin{array}{l}\text { Professionals in internal auditing have excellent } \\
\text { compensation and benefits. (benefits) }\end{array}$ & $0.80(1.12)$ & $\mathrm{t}=14.82^{* * *}$ \\
\hline 4. & $\begin{array}{l}\text { Professionals in internal auditing perform } \\
\text { meaningful and satisfying work. (work) }\end{array}$ & $0.64(1.36)$ & $\mathrm{t}=9.83^{* * *}$ \\
\hline 5. & $\begin{array}{l}\text { Professionals in internal auditing have excellent } \\
\text { promotion and career opportunities. (promotion) }\end{array}$ & $0.63(1.20)$ & $\mathrm{t}=10.86^{* * *}$ \\
\hline 6. & $\begin{array}{l}\text { Professionals in internal auditing have excellent } \\
\text { work life balance. (balance) }\end{array}$ & $0.04(1.13)$ & $\mathrm{t}=0.77$ \\
\hline
\end{tabular}

Questions were measured on a 7 point scale with -3 labeled "Strongly Disagree," -2 labeled "Disagree," -1 labeled "Somewhat Disagree," 0 labeled "Neither Agree nor Disagree," 1 labeled "Somewhat Agree," 2 labeled "Agree," and 3 labeled "Strongly Agree."

Panel B: Perceptions of Institutions Discussion of and Favorability towards Internal Audit

\begin{tabular}{|l|c|c|}
\hline Attribute & Mean (StD) & T-test: Mean =0 \\
\hline $\begin{array}{l}\text { At my university, internal auditing is often discussed as a } \\
\text { career for students. (UniversityDiscussed) }\end{array}$ & $-0.45(1.65)$ & $\mathrm{t}=-5.66^{* * *}$ \\
\hline $\begin{array}{l}\text { At my university, discussion about internal auditing is } \\
\text { positive. (UniversityPositive) }\end{array}$ & $0.36(1.12)$ & $\mathrm{t}=6.75^{* * *}$ \\
\hline
\end{tabular}

Questions were measured on a 7 point scale with -3 labeled "Strongly Disagree," -2 labeled "Disagree," -1 labeled "Somewhat Disagree," 0 labeled "Neither Agree nor Disagree," 1 labeled "Somewhat Agree," 2 labeled “Agree," and 3 labeled "Strongly Agree."

***,**,* signify p-values $<0.01,0.05$, and 0.1 , respectively. P-values are one-tailed when a directional prediction is made and the results are consistent with the predictions. 
TABLE 3

Test of $\mathrm{H} 2$ and H3s: Willingness of Business Professionals to Apply for a Job Described as Internal Audit or Not

Panel A: Mean (Std) Percent of Respondents Willing to Apply to Work in Advertised Position

\begin{tabular}{lccccccc}
\hline \hline & Baseline & Assurance & Consulting & MTG & No MTG & Outsourcing & Overall \\
\cline { 2 - 7 } General Employee Position & $42.4(50.2)$ & $42.5(50.1)$ & $60.0(49.8)$ & $68.6(47.1)$ & $75.8(43.5)$ & $45.7(50.5)$ & $55.3(49.8)$ \\
Internal Audit & $37.5(49.2)$ & $36.7(49.0)$ & $48.6(50.7)$ & $46.7(50.7)$ & $47.1(50.7)$ & $38.2(49.3)$ & $42.6(49.6)$ \\
Difference & 4.9 & 5.8 & 11.4 & 21.9 & 28.7 & 7.5 & 12.7 \\
$\boldsymbol{X}^{\mathbf{2}}$ & 0.164 & 0.243 & 0.849 & $3.192 * *$ & $5.808 * * *$ & 0.396 & $6.542 * * *$ \\
\hline \hline
\end{tabular}

Panel B: Graph of Panel A Averages

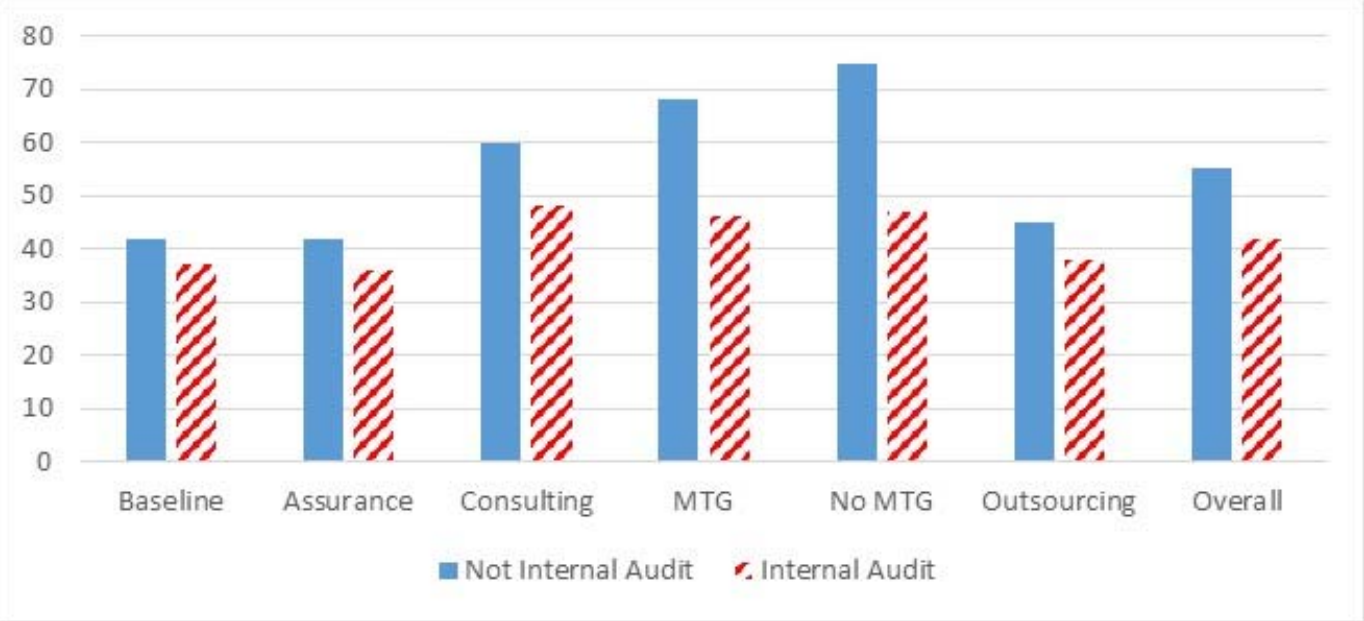

Panel C: ANOVA Comparison of All Conditions

\begin{tabular}{lrrr}
\hline \hline Source & \multicolumn{1}{c}{ SS } & F-Value & \multicolumn{1}{c}{ P-value } \\
\hline InternalAudit & 1.93 & 8.15 & 0.002 \\
Condition & 4.18 & 3.52 & 0.002 \\
InternalAudit*Condition & 1.31 & 1.10 & 0.359 \\
\hline \hline
\end{tabular}


Panel D: ANOVA Comparison of Only Internal Audit Conditions

\begin{tabular}{lrrr}
\hline \hline Source & SS & F-Value & \multicolumn{1}{c}{ P-value } \\
\hline Condition & 0.68 & 0.53 & 0.752 \\
\hline \hline
\end{tabular}

Panel E: ANOVA Comparison of Only Non-Internal Audit Conditions

\begin{tabular}{lrrr}
\hline \hline Source & SS & F-Value & \multicolumn{1}{c}{ P-value } \\
\hline Condition & 4.94 & 4.42 & $<0.001$ \\
\hline \hline
\end{tabular}

Panel F: Comparison of Willingness to Switch into or out of Internal Audit Department

\begin{tabular}{lcc}
\hline & Mean (StD) & T-test: Mean $=\mathbf{4}$ \\
\cline { 2 - 3 } $\begin{array}{l}\text { Willingness to Pursue Internal Audit: Score } \\
\text { above (below) } 4 \text { suggest willingness to switch } \\
\text { out of (into) internal audit }\end{array}$ & $4.65(1.50)$ & $\mathrm{t}=9.02 * * *$ \\
\hline \hline
\end{tabular}

$* * *, * *, *$ signify p-values $<0.01,0.05$, and 0.10 , respectively. P-values are one-tailed when a directional prediction is made and the results are consistent with the predictions. In Panels C, D, and E, dummy variables are included for universities for which participants are from. None of the university variables are significant and are not presented. For Panel F, participants were asked: "You find out there is an identical job posting for a similar company with one difference. The new job would hire you to work in a department other than the internal audit function of the company (or to work in the internal audit function of the company). Which job would you be more interested in pursuing?" Participants were shown the opposite choice to the job description they just read in the experiment.

Answers were measured on a seven-point scale anchored at "1 - Strongly prefer the job in the internal audit function of the company," "4 - Prefer each position equally," and "7 - Strongly prefer the job in a department other than the internal audit function of the company." Other variables are defined as follows:

InternalAudit $=$ A dichotomous variable equal to one if the job description used the word internal audit and zero if the job description did not specifically describe the position (e.g., used the term "employee").

Condition $\quad=$ A variable ranging from one to six, taking a different value for each condition (i.e., Baseline, Assurance, Consulting, MTG, No MTG, and Outsourcing). 
TABLE 4

\section{Examination of Factors Influencing Decision to Apply to Work in Internal Audit}

\begin{tabular}{lcccc}
\hline \hline & Expectation & Estimate & $\chi^{\mathbf{2}}$ value & P-value \\
\cline { 2 - 5 } Intercept & $+/-$ & 0.985 & 2.02 & 0.155 \\
IA Characteristics & + & 0.613 & 10.65 & 0.001 \\
University Perceptions & + & 0.146 & 1.24 & 0.133 \\
Multiple Choice Score & + & 0.01 & 0.02 & 0.445 \\
Top Performer & - & -0.221 & 3.50 & 0.031 \\
Male & $+/-$ & -0.109 & 0.61 & 0.435 \\
Internships & $+/-$ & -0.623 & 2.60 & 0.107 \\
Accepted Offer & $+/-$ & 0.004 & 0.61 & 0.435 \\
Business Experience & $+/-$ & 0.985 & 2.02 & 0.155 \\
\hline \hline
\end{tabular}

The dependent variable is a dichotomous variable taking the value of one if participants are willing to apply to work in the internal audit position and zero otherwise. Only participants in the situation with internal auditing are included as perceptions of internal auditing are not expected interest in applying for a non-internal audit position. The $\mathrm{R}^{2}$ for the logistic regression is 0.114. Variables are defined in Tables 2, 3, and as follows:
IACharacteristics $\quad=$ The average of the variables Respected, Benefits, Work, Promotion, Balance, and Stereotypes (which is subtracted rather than added to compute the average). Table 2, Panel A defines these variables.
University Perceptions $=$ The average of UniversityDiscussed and UniversityPositive. Table 2, Panel B defines these variables.
Multiple Choice Score $=$ The percentage score participants answered correctly on a 14 question test. The questions were CIA practice exam questions given on the IIA's website.
Top Performer $\quad=$ Participants were asked to indicate their agreement with the statement: "I am one of the top performing students in my class." The scale was measured on a 7-point scale labeled 1 - strongly disagree, 2 - disagree, 3 - somewhat disagree, 4 - neither agree nor disagree, 5 - somewhat agree, 6 - agree, 7 - strongly agree.
Male
$=$ A dichotomous variable taking the value of 1 if male and 0 if female.
Internships
AcceptedOffer
= A variable measuring how many internships participants had completed.
$=$ A dichotomous variable taking the value of 1 if the participant had accepted a job offer and 0 if they had not. 
TABLE 5

Survey Results of Factors that would Increase Interest in Working in Internal Audit for Low and High Academically Performing Students

\begin{tabular}{lcc} 
Topic & Below Median GPA & Above Median GPA \\
\hline Less Boring/Tedious Work & $13.3 \%(4)$ & $21.9 \%(7)$ \\
No Interest/Not a Good Fit & $10 \%(3)$ & $21.9 \%(7)$ \\
Better Pay Incentive & $43.3 \%(13)$ & $15.6 \%(5)$ \\
Work in a preferred company/field & $3.3 \%(1)$ & $12.5 \%(4)$ \\
More Understanding of Career & $0 \%(0)$ & $12.5 \%(4)$ \\
Other Factors & $13.3 \%(4)$ & $6.3 \%(2)$ \\
Work/Life Balance & $3.3 \%(1)$ & $6.3 \%(2)$ \\
More Creativity/Flexibility & $13.3 \%(4)$ & $3.1 \%(1)$
\end{tabular}

Survey responses from 46 participants ( 4 additional did not provide sufficient data for analysis). Participants responded to the question, "What factors would make it so you would be more likely to pursue a career in internal audit? Or said differently, what would have to change about internal auditing for you to more strongly consider it as a possible career?" A research assistant created groupings of responses and categorized responses into those groupings. Participants could record as many responses as they would like, and each individual suggestion is considered a separate response. Responses are split at the median of self-reported GPA (3.6). Parentheses indicate the raw number of responses. 